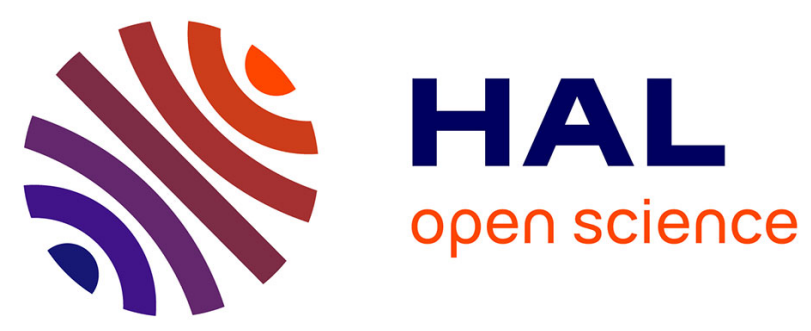

\title{
Short term effects of various water immersions on recovery from exhaustive intermittent exercise
}

Hervé Pournot, François Bieuzen, Rob Duffield, Pierre-Marie Leprêtre, Christophe Cozzolino, Christophe Hausswirth

\section{- To cite this version:}

Hervé Pournot, François Bieuzen, Rob Duffield, Pierre-Marie Leprêtre, Christophe Cozzolino, et al.. Short term effects of various water immersions on recovery from exhaustive intermittent exercise. European Journal of Applied Physiology, 2011, 111 (7), pp.1287-1295. 10.1007/s00421-010-1754-6 . hal-01724330

\section{HAL Id: hal-01724330 https://hal-insep.archives-ouvertes.fr/hal-01724330}

Submitted on 6 Mar 2018

HAL is a multi-disciplinary open access archive for the deposit and dissemination of scientific research documents, whether they are published or not. The documents may come from teaching and research institutions in France or abroad, or from public or private research centers.
L'archive ouverte pluridisciplinaire HAL, est destinée au dépôt et à la diffusion de documents scientifiques de niveau recherche, publiés ou non, émanant des établissements d'enseignement et de recherche français ou étrangers, des laboratoires publics ou privés. 


\title{
Short term effects of various water immersions on recovery from exhaustive intermittent exercise.
}

\author{
HERVE POURNOT ${ }^{1,2}{ }^{2}$, FRANCOIS BIEUZEN ${ }^{1}$, ROB DUFFIELD ${ }^{3}$, PIERRE-MARIE LEPRETRE ${ }^{4}$, \\ CHRISTOPHE COZZOLINO ${ }^{5}$, CHRISTOPHE HAUSSWIRTH ${ }^{1}$ \\ Publié dans : European journal of applied physiology, 2010, vol.111, n²7, pp. 1287-1295 \\ ( doi : 10.1007/s00421-010-1754-6 ISSN 1439-6319 PMID : 21132438) \\ ${ }^{1}$ Research Department, National Institute of Sport, Expertise and Performance (INSEP), Paris, France \\ ${ }^{2}$ Laboratory of Physiological Adaptations, Motor Performance and Health (EA 3837), Faculty of Sport \\ Sciences, University of Nice-Sophia Antipolis, BP 32 59, 06205 Nice Cedex 03, France \\ ${ }^{3}$ Exercise and Sports Science Laboratory, School of Human Movement Studies, Charles Sturt \\ University, Bathurst, New South Wales, Australia \\ ${ }^{4}$ University of Picardie Jules Verne, 80025 Amiens Cedex, France \\ ${ }^{5}$ Department of High level Sport, National Institute of Sport, Expertise and Performance (INSEP), \\ Paris, France
}

\section{Corresponding author:}

Dr. Bieuzen François, PhD.

Research Department, National Institute of Sport, Expertise and Performance (INSEP),

11 avenue du Tremblay 75012 Paris (France) 


\section{Abstract}

POURNOT, H., BIEUZEN, F., DUfFIELD, R., LEPRETRE, PM., COZZOLINO, C., HAUSSWIRTH, C. Short term effects of various water immersions on recovery from exhaustive intermittent exercise. Purpose: To investigate the effectiveness of different techniques of water immersion recovery on maximal strength, power and the post-exercise inflammatory response in elite athletes. Methods: Forty one highly trained (Football, Rugby, Volleyball) male subjects (age $=21.5 \pm 4.6$ years, mass $=$ $73.1 \pm 9.7 \mathrm{~kg}$ and height $=176.7 \pm 9.7 \mathrm{~cm}$ ) performed $20 \mathrm{~min}$ of exhaustive, intermittent exercise followed by a 15 min recovery intervention. The recovery intervention consisted of different water immersion techniques, including: temperate water immersion $\left(36^{\circ} \mathrm{C} ; \mathrm{TWI}\right)$, cold water immersion $\left(10^{\circ} \mathrm{C} ; \mathrm{CWI}\right)$, contrast water temperature $\left(10-42^{\circ} \mathrm{C} ; \mathrm{CWT}\right)$, and a passive recovery (PAS). Performances during a maximal $30-\mathrm{sec}$ rowing test $\left(\mathrm{P}_{30 \mathrm{sec}}\right)$, a maximal vertical counter-movement jump (CMJ) and a maximal isometric voluntary contraction (MVC) of the knee extensor muscles were measured at rest (Pre-exercise), immediately after the exercise (Post-exercise), 1 hour after (Post $1 \mathrm{~h}$ ) and 24 hours later (Post 24h). Leukocyte profile and venous blood markers of muscle damage (creatine kinase (CK) and lactate dehydrogenase (LDH)) were also measured Pre-exercise, Post1h and Post24h. Results: A significant time effect was observed to indicate a reduction in performance (Pre-exercise vs. Postexercise) following the exercise bout in all conditions $(p<0.05)$. Indeed, at $1 \mathrm{~h}$ post exercise, a significant improvement in MVC and $\mathrm{P}_{30 \text { sec }}$ was respectively observed in the CWI and CWT groups compared to pre-exercise. Further, for the CWI group, this result was associated with a comparative blunting of the rise in total number of leucocytes at $1 \mathrm{~h}$ post and of plasma concentration of $\mathrm{CK}$ at $24 \mathrm{~h}$ post. Conclusions: The results indicate that the practice of cold water immersion and contrast water therapy are more effective immersion modalities to promote a faster acute recovery of maximal anaerobic performances (MVC and 30" all-out respectively) after an intermittent exhaustive exercise. These results may be explained by the suppression of plasma concentrations of markers of inflammation and damage, suggesting reduced passive leakage from disrupted skeletal muscle, which may result in the increase in force production during ensuing bouts of exercise.

Key words: INTERMITTENT EXERCISE, FATIGUE, MUSCLE DAMAGE, RECOVERY, WATER IMMERSION, PERFORMANCE, HIGH TRAINED ATHLETES. 


\section{Introduction}

A common issue confronting most highly trained team sport athletes is the limited time available for full physiological recovery between training sessions and/or games. Excessive volumes of intense training and competition, particularly with minimal recovery time, can place great physiological constraints on the musculoskeletal system and potentially cause symptoms of overreaching, fatigue and result in the suppression of performance (Reilly and Ekblom 2005). Based on these observations, the need to maximize recovery periods and modalities appears to be important to speed performance restoration. Moreover, training or competition induced EIMD can result in a release of inflammatory mediators and myocellular enzymes into the plasma. Accordingly, serum creatine kinase (CK) has been reported to characterize muscle membrane disruption, and has been extensively measured within the literature as a biological marker of muscle damage (Brancaccio et al. 2008; French et al. 2008; Howatson et al. 2009; King and Duffield 2009; Reilly and Ekblom 2005). Indeed, in situ studies report peak plasma concentrations (i.e., creatine (CK), lactate dehydrogenase (LDH), leukocytes) may be associated with the decline in performance during the 48 h following matches (Ispirlidis et al. 2008; Rowsell et al. 2009). In addition, Rodenburg (1993) reported a significant positive correlation between percentage of torque loss during a maximal isometric voluntary contraction (MVC) and the level of plasma CK increases. As such, team sport athletes are often exposed to exhaustive and EIMD type activities during generic training and specific competitive bouts, and the use of recovery modes may be of importance to aid preparation for ensuing sessions.

Recovery is defined as the return of the muscle to its pre-exercise state following exercise (Tomlin and Wenger 2001). It is suggested that the use of recovery strategies ensures performance in subsequent exercise sessions (training and/or competition) are not unduly compromised by lingering muscle soreness or decrements in power or speed of movement (King and Duffield 2009). Among different methods of recovery interventions utilised following exercise, water immersion interventions, including, cold, temperate and contrast, are popular procedures used in many sports. Cold water immersion (CWI) is commonly used following acute musculoskeletal injuries to induce vasoconstriction and has recently been proposed to enhance both physiological and perceptual recovery (Bailey et al. 2007; Eston and Peters 1999; Gill et al. 2006). Further, in theory the effects of hydrostatic pressure associated with cold temperature or both hot and cold therapy may result in both muscular and vascular compression and therefore assist the reduction of early onset swelling and inflammation (Goodall and Howatson 2008). The technique of alternating hot-cold water or contrast water temperature therapy (CWT) is proposed to create a "vaso-pumping" action through alternating vasodilatation and vasoconstriction of the blood vessels due to temperature changes 
(Cochrane 2004; Hing et al. 2008). The alterations in peripheral vessel constriction are proposed to increase blood flow and enhance the removal of metabolic by-products, consequently speeding recovery (Bailey et al. 2007; Vaile et al. 2008a, b). To date, such recovery interventions are being employed in field environments, despite limited scientific evidence regarding their potential benefits and/or mechanisms by which they may work (Vaile et al. 2008c). Further, treatment protocols vary with regard to the duration and frequency of immersions and the temporal relationship with exercise, possibly explaining the inconsistency in the collection of reported results regarding the recovery of strength and muscle soreness (Goodall and Howatson 2008; Sellwood et al. 2007). Indeed Gill et al. (2006) have reported an enhancement of the rate of CK clearance after an elite rugby match using CWT. Further, this study did not use muscular performance measures to explain the physiological relevance of the CK results to actual performance. In this context, Vaile et al. (2008b) demonstrated performance differences in time-trial cycling following use of either CWI or CWT recovery modes (in highly trained cyclists). Moreover, Ingram et al. (2009) used either CWI or CWT recovery; however, did not report any differences in the rate of CK release $24 \mathrm{~h}$ post exercise.. Finally, Rowsell et al. (2009) demonstrated that both immersion in temperate water (TWI) $\left(34^{\circ} \mathrm{C}\right)$ and $\mathrm{CWI}\left(10^{\circ} \mathrm{C}\right)$ did not improve performance in vertical jump and $20-\mathrm{m}$ sprint performance in highperformance junior soccer players.

Despite these mixed findings, CWI and other forms of hydrotherapy are popular tools to enhance recovery following training and competition in elite athletes. To date, research on the use of post-exercise recovery using immersion therapy has been conducted on recreational athletes, whose body composition and physiological components may be vastly different from elite or high performance level athletes (Halson et al. 2008).. These results suggest that such immersion therapies applied to athletes of a greater capability may result in different time profiles of physiological and performance restoration (Ravier et al. 2006; Sellwood et al. 2007; Vaile et al. 2008b). In this context we hypothesized that a 24-h time of recovery after using CWI is more efficient against potentially harmful effects of inflammation and on the restitution of maximal anaerobic performance compared with passive recovery (PAS) or other hydrotherapy immersion (TWI, CWT). Therefore, to determine the impact of these recovery strategies on high performance athletes, the aim of this study was to consider the effectiveness of three hydrotherapy interventions (CWI, TWI and CWT) in comparison to PAS on anaerobic performance and removal of waste products.

\section{Methods}

SUBJECTS 
A total of 41 elite athletes $\left(21.5 \pm 4.6 \mathrm{yr}, 73.1 \pm 9.7 \mathrm{~kg}, 176.7 \pm 9.7 \mathrm{~cm}, \mathrm{VO}_{2}\right.$ max: $65.6 \pm 3.2$ $\mathrm{ml} \cdot \mathrm{min}^{-1} \cdot \mathrm{kg}^{-1}$ ) volunteered to participate in this study. All subjects were high performance athletes who competed in National and International level competition for Football, Rugby or Volleyball, respectively. Participants trained six to ten times a week and competed at National and/or International level for at least five years. After being informed of all details of the experimental procedures and methods, the associated benefits and the potential risks of the investigation, each subject completed a written consent in accordance with ethics committee for the protection of individuals (Île-de-France XI, France; Ref. 09015). Ethics was approved by the Institutional Ethics committee. The day before and throughout the duration of the study, the subjects refrained from consumption of any anti-inflammatory pills and did not use any additional methods to aid recovery (i.e. stretching, massage or active recovery). Participants completed food and activity diaries to standardise hydration and nutrition during the week prior to each session and no caffeine was ingested before and throughout the duration of the tests.

\section{EXPERIMENTAL DESIGN}

An overview of the experimental protocol is presented in Figure 1. Prior to all testing sessions, subjects were randomly distributed in one of the following recovery groups: CWT, CWI, TWI and a control group (PAS). TWI, CWI, CWT \& PAS were composed of 9, 13, 10 and 9 subjects, respectively. All subjects were previously habituated with each measure via normal sports specific testing and training procedures within the Institution. Subjects habitually use rowing ergometer after each game or training session as part of cool down procedures and regularly practice intermittent exhaustive exercise during conditioning sessions. Each respective recovery condition was conducted over two consecutive days of testing. All subjects completed an exhaustive intermittent exercise protocol involving counter-movement jump and rowing to invoke sufficient fatigue and muscle damage. Prior to and immediately, $1 \mathrm{~h}$ and $24 \mathrm{~h}$ following the exercise protocol, a series of maximal anaerobic power and strength assessment tests were performed. The maximal test dependent variables included a maximal isometric voluntary contraction (MVC) of the knee extensors, a maximal counter-movement jump (CMJ) and finally mean power during 30-sec all-out rowing test $\left(\mathrm{P}_{30 \mathrm{sec}}\right)$ to determine anaerobic capacity. Venous blood samples were collected to measure markers of (CK and LDH) and haematological profile were analyzed to reflect both muscle damages and inflammation prior to, $1 \mathrm{~h}$ and $24 \mathrm{~h}$ after the intermittent exercise protocol. All blood samples were obtained before the explosive strength and anaerobic capacity tests to avoid any potential acute effect of test performance on blood measures.

[Insert Figure 1] 
The exhaustive intermittent exercise protocol consisted of two bouts of $10 \mathrm{~min}$, separated by a rest period of $10 \mathrm{~min}$. Each bout consisted of a $10 \mathrm{~min}$ circuit consisting of alternating $30-\mathrm{sec}$ of CMJ (frequency imposed: $0.7 \mathrm{~Hz}$ ), and $30-\mathrm{sec}$ rowing at power corresponding to $80 \%$ of $\mathrm{P}_{30 \mathrm{sec}}$, each followed by a recovery period of $30 \mathrm{sec}$. This protocol generated both metabolic and local muscular fatigue comparable to the demands of training or competition (Magalhaes et al. 2010).

\section{RECOVERY MODALITIES}

Following the exercise protocol and post test measures, each recovery group was immersed underwater in a sitting position to the level of the iliac crest for $15 \mathrm{~min}$ in a dedicated bath, while the PAS group remained seated on a chair for $15 \mathrm{~min}$. CWI and TWI were continuously immersed in water temperatures of $10{ }^{\circ} \mathrm{C}$ and $36^{\circ} \mathrm{C}$, respectively. The CWT group alternated immersion at $10{ }^{\circ} \mathrm{C}$ and $42{ }^{\circ} \mathrm{C}$ with 5 cycles of $1 \mathrm{~min} 30 \mathrm{sec}$ in each bath.

\section{PERFORMANCE}

MVC was assessed using an isokinetic dynamometer (Biodex System 3, Biomedical Systems, Newark, CA, USA). The device was set-up according to the manufacturer's recommendations to exercise the knee extensors muscles of the non-dominant leg. The anatomical zero level was set at a knee angle of $0^{\circ}$ (full extension). MVC was then determined by setting the joint angle at $70^{\circ}$ of flexion and locked in place and marked to ensure consistency during subsequent testing sessions. Prior to the beginning of each test, the limb weight and moment acting upon the dynamometer power head were corrected for gravity. Three attempts of 3-sec were performed, each separated by a 60 -sec rest period. The peak force obtained during the $3 \mathrm{sec}$ effort was defined as the MVC.

The maximal jump height was measured during CMJ using an isoinertial dynamometer (Pro Myotest, Sion, Switzerland) and previously validated by Jidovtseff et al. (2008). Subjects were asked to place hands on their hips to prevent the influence of arm movement on vertical jump performance. Kneebend during the CMJ was standardized based on the use of a goniometer to determine the degree of knee flexion prior to each jump. Subjects performed three maximal CMJ starting from a standing position, with a $1 \mathrm{~min}$ recovery period between respective jumps. Subjects were required to perform maximal efforts, with only the best jump height recorded for subsequent analyses.

$P_{30 \text { sec }}$ was determined during a maximal 30 sec effort on a Concept II rowing ergometer (Morrisville, VT, USA). Subjects were harnessed to the rower's seat with a strap to the hips and instructed to perform a maximal $30 \mathrm{sec}$ effort to reach and maintain the highest Wattage (W) output as fast as 
possible. The average power output over $30 \mathrm{sec}\left(P_{30 \mathrm{sec}}\right)$ was recorded. This value was used to determine the target to maintain the power output during the fatiguing exercise corresponding to $80 \%$ of the $\mathrm{P}_{30 \mathrm{sec}}$. Power output values displayed by the ergometer for each stroke were calculated by the C2D system as previously described (Boyas et al. 2006) and recorded using the RowPro ${ }^{\mathrm{TM}} 1.7$ software (Digital Rowing Inc., Boston, MA, USA).

\section{BLOOD SAMPLING AND PROCESSING}

Venous blood samples were collected pre-exercise and at two time points following exercise (Post $1 \mathrm{~h}$ and Post 24h). Each blood sample (12-ml) was collected from a superficial forearm vein using standard venipuncture techniques. All samples were directly evacuated into serum separator (2 Vacutainer tubes lithium heparin $=4 \mathrm{ml}$ and 1 Vacutainer tube EDTA $=4 \mathrm{ml}$ ) collection tubes (Greiner Bio-one; Frickenhausen, Germany).

ENZYMATIC ANALYSES - The blood contained within lithium heparin tubes was centrifuged at 3000 for $10 \mathrm{~min}$ rev. $\mathrm{min}^{-1},+4{ }^{\circ} \mathrm{C}$ to separate serum. Serum samples were frozen at- $80^{\circ} \mathrm{C}$ until analysis. $\mathrm{CK}$ and LDH concentrations were then determined from serum using a Hitachi 911 automated clinical chemistry analyzer (Roche Diagnostics Corporation, Indianapolis, IN, USA) and commercially available reagents (Roche Diagnostics Corporation, Indianapolis, IN, USA).

LEUKOCYTE COUNT - Centrifuged Blood from EDTA tube were analysed for leukocyte count using an automated cell counter (Cell-Dyn ${ }^{\circledR}$ Ruby $^{\mathrm{TM}}$, Abbott, IL, USA).

The inter- and intra- assay coefficients of variation in all assays performed were 2.2 to 6.2 and 3.0 to 6.5 respectively.

\section{DELAYED ONSET MUSCLE SORENESS (DOMS)}

DOMS was determined by a standardized half squat to ensure all subjects were experiencing the same movement/ sensation. Perceived soreness was then rated on a visual analogue scale (VAS). Subjects were required to rank their perception of soreness on a scale of 0 "normal" to 10 "extremely sore" at Pre-exercise, Post-exercise and $24 \mathrm{~h}$ post exercise. This method has been used previously as non invasive way to monitor changes in perceived pain following muscle damaging protocols (Vaile et al. 2008c).

STATISTICAL ANALYSES 
All variables were expressed as mean and standard deviation (Mean $\pm S D$ ). Differences in the measured variables among conditions and trials were analyzed with two-ways ANOVA for repeated measures (Recovery modality $\times$ Time, $4 \times 4$ or Recovery modality $\times$ Time, $4 \times 3$ ), using recovery modality as the between subject factor and time as the within-subjects factors. Newman-Keuls post hoc test was used to determine any difference among recovery modalities and over time. Data were analyzed using Statistica 7 for Windows (StatSoft, Inc. TULSA, Oklahoma, USA) and the level of significance was set at $p<0.05$.

\section{Results}

\section{EXPLOSIVE-STRENGTH AND HIGH INTENSITY EXERCISES}

All subjects completed the exercise protocol with no significant differences in power observed between groups on Pre-exercise or Post-exercise measures for any performance variable $(P<0.05)$. As such, a similar performance and physiological state existed before and after the exercise protocol for all groups. Nevertheless, there was a significant main effect $(P<0.05)$ for time noted in the change in performance measures following the respective recovery interventions.

MVC, CMJ and $P_{30 \text { sec }}$ values of all groups decreased significantly $(P<0.05)$ immediately after the exhaustive exercise bout in all groups (Post-exercise) (figure 2). Post-1h data indicated that a suppressed performance state remained evident for all groups except for the MVC and CMJ measures of CWI group and $\mathrm{P}_{30 \text { sec }}$ measure of CWT group, which were not significantly lower than Pre-exercise values. $24 \mathrm{~h}$ post measures of MVC and $\mathrm{P}_{30 \text { sec }}$ indicated that a suppressed performance state remained evident for all groups except for the CWI and CWT groups, which were not significantly lower than Pre values (figure 2).

\section{[Insert Figure 2]}

\section{BLOOD ANALYSES}

ENZYMATIC ANALYSES - Compared with measures in pre-exercise condition, 24h post exercise the concentrations in plasma $C K$ showed a significant increase $(P<0.05)$ for each group except $C W I$. No significant $(P>0.05)$ increase of $L D H$ was measured at Post $1 \mathrm{~h}$ and Post $24 \mathrm{~h}$ compared to resting measures except for the CWT group at Post $1 \mathrm{~h}$.

\section{[Insert Figure 3]}


LEUKOCYTE COUNT - Post $1 \mathrm{~h}$ values of the PAS, TWI and CWT groups showed a significant $(p<0.05)$ rise in the total number leukocytes, neutrophils and monocytes from the resting measures. Conversely, CWI values have not changed $(P>0.05)$. However, $24 \mathrm{~h}$ following exercise, no significant differences ( $P>0.05)$ were apparent either between conditions or to Pre-exercise testing measures (Table 1 ).

\section{[Insert Table 2]}

\section{DOMS}

Finally, perceived muscle soreness (DOMS) was significantly $(P<0.05)$ increased 24 hours post exercise in all groups (CWI, CWT, TWI and PAS) compared to Pre-exercise testing measures. No difference between groups were observed before or after fatiguing exercise $(P>0.05)$

\section{[Insert Figure 4]}




\section{Discussion}

The purpose of this study was to investigate the effectiveness of four different recovery modalities of cold water immersion (CWI), temperate water immersion (TWI) or contrast water temperature (CWT) compared to passive (PAS) recovery on anaerobic performance and markers of EIMD. We ventured the hypothesis that in the short term (24h), highly trained athletes (elite International standard) immersed in cold water would show a speedier recovery of performance and markers of EIMD. Indeed, in the present study, the following findings were evident; 1) CWI recovery resulted in faster recovery of MVC and CMJ at $1 \mathrm{~h}$ post compared to Pre-exercise measures; 2) CWT recovery resulted in faster recovery of $\mathrm{P}_{30 \text { sec }}$ values at $1 \mathrm{~h}$ post compared to Pre-exercise measures; 3 ) $\mathrm{CWI}$ resulted in a blunted CK $24 \mathrm{~h}$ response following exercise; 4) $\mathrm{CWI}$ also suppressed the rise in neutrophil, monocyte and the total number of leukocyte count $1 \mathrm{~h}$ post-exercise.

In the current study, CWT therapy resulted in an improved recovery of $\mathrm{P}_{30 \mathrm{sec}} 1 \mathrm{~h}$ after the exhaustive exercise protocol, where in contrast, CWI and TWI showed minimal improvement in recovery. These findings are in accordance with previous research on recreational subjects utilizing CWT (Coffey et al. 2004; Versey et al. 2010) or CWI (Stacey et al. 2010) therapy following similar exercise intensities and/or bouts. To the best of the authors knowledge, no previous research uses a subject population of such international (elite) calibre, and accordingly, where the highly trained status of the subject population may predispose them to a faster recovery than untrained populations (Ravier et al. 2006). Similar to previous studies (Coffey et al. 2004; Versey et al. 2010), the current findings highlight that CWT may promote the maintenance of performance during maximal exercise in the short term $(<1 \mathrm{~h})$ compared to passive recovery or other immersion therapies. While it must be noted that the change in performance between the groups was $28 \%$, for elite athletic populations, such improvements may be beneficial for continued training quality. The observed suppression and recovery of the present MVC and CMJ data might reflect exercise-induced skeletal muscle cell structure damages or disruption (Friden and Lieber 1992). The present data demonstrated significant increases $1 \mathrm{~h}$ post exercise following the use of the $\mathrm{CWI}$ intervention compared to other conditions; whereas CWT therapy data indicated that a suppressed performance state for MVC was not evident $24 \mathrm{~h}$ post exercise. The improvement of MVC with CWI at $24 \mathrm{~h}$ post exercise is in accordance with previous findings (Bailey et al. 2007; Vaile et al. 2008c) but, to the best of our knowledge, is yet to be reported $1 \mathrm{~h}$ post-exercise. Moreover, in contrast, Vaile et al. (2007) reported CWT therapy did not attenuate any post-exercise force loss. 
The aforementioned contrasting performance findings may be present due to the treatments

2 (CWT and CWI) and might suggest the importance of the duration of cold exposure for athletes. Indeed, CWI protocols are suggested to require a longer period of immersion time in cold water compared to CWT (Wilcock et al. 2006). It is possible that this might lead to more significant physiological changes than CWT or CWI interspaced by PAS (Hing et al. 2008). Further, any CWI induced vasoconstriction may require more time in water than 1-2 min and thus the difference in immersion or exposure time and temperature $\left(15^{\circ} \mathrm{C}-12 \mathrm{~min}\right.$ vs. $10^{\circ} \mathrm{C}-15 \mathrm{~min}$ in the present study) may explain the contrasting results of the aforementioned studies. Alternatively, the effect of temperature per se as opposed to the induced hydrostatic pressure was tested with the use of the TWI condition, which could cause a 'squeezing' and displacement of fluid from the lower extremities into the thoracic region (Lollgen et al. 1981). Moreover, for mechanical effects of CWT, Cochrane (2004) suggested that the significant skin temperature fluctuations from the hot-cold would cause vasoconstriction and vasodilatation thereby initiating subcutaneous response and mechanical shunting. Accordingly, the positive effect from CWT and the lack of positive effect from TWI or CWI suggests that the recovery from a fatigued state may be mainly attributed to the localized cooling effect to the periphery and possible effect on intra-muscular blood flow or contractile elements (Cochrane 2004).

Previously, it has been suggested that lower MVC torque measured after maximal intensity exercise is primarily a result of the presence of contractile trauma, in turn, which may present as increased venous blood CK concentrations (Rodenburg et al. 1993). Further, contractile apparatus disruption may also be evident by post-exercise elevations in inflammatory markers of white blood cell counts (Smith et al. 2008). In regard to the present study, only in the CWI condition were the changes in leucocyte and CK concentrations blunted at $1 \mathrm{~h}$ and $24 \mathrm{~h}$ respectively. The present findings are consistent with those of similar investigations using cold water immersion therapy as a modality to treat EIMD (Bailey et al. 2007). Importantly, the intensity and duration of exercise used to elicit muscle damage resulted in severe muscle soreness and an associated period of muscular dysfunction (i.e. MVC and CMJ), comparable to previously documented studies (Goodall and Howatson 2008; Ispirlidis et al. 2008). Additionally, the overall increase in intracellular proteins (CK) present in venous blood, reflecting the balance of the rate of clearance versus rate of appearance, was of a similar volume and time course as observed in previous investigations on recreational athletes (French et al. 2008; Howatson et al. 2009; Ingram et al. 2009). Given the similar workload and exercise-induced reductions in power between respective groups in the present study, the suppression of CK suggests either a slower appearance or faster clearance following CWI. As highlighted earlier, local cooling is likely to alter skeletal blood flow (Vaile et al. 2010), and may limit the passive leakage of intra-cellular 
elements that are used as indirect markers of muscle damage. The corollary improvement in muscle performance may represent a functional outcome of this reduced efflux of $\mathrm{CK}$, or some other mechanism yet to be determined.

Previous researchers postulated that the use of CWI post-exercise might attenuate the induced muscle damage inflammatory response due to a decrease permeability of blood and lymph vessels reducing the efflux of muscle damage markers from skeletal muscle (Eston and Peters 1999). Thus, the lower CK concentrations via the reduction of cellular, lymphatic and capillary permeability may be explain by localized vasoconstriction induced by the cooler temperature (Eston and Peters 1999) of CWI condition. Further, this reduced diffusion rate may assist in reducing acute inflammation from muscle damage and immune activation (Coté et al. 1988; Stacey et al. 2010). In turn, the reduced inflammation can reduce pain, swelling and the loss of force generation that is also often associated with the inflammatory process (Goodall and Howatson 2008; Smith 1991). However, in contrast to Vaile et al. (2007), we did not observe a significant effect of CWT to reduce postexercise CK values. These authors suggested that CWT causes alterations in the perfusion of the muscle via alternating vasodilatation and vasoconstriction, which might attenuate the immune response and therefore reduce myocellular damage. This result may be due to differences in the CWT protocol, and in particular, on the duration exposure (90 sec for present study vs. $120 \mathrm{~s}$ ). Unlike the change in CK and considering the noted decrease in MVC torque, LDH was not elevated above baseline in any group. This is consistent with work by Friden et al. (1983) who also found an elevation in serum $[C K]$ with no change in serum $[\mathrm{LDH}]$, although the fatiguing exercise was an eccentric bout of the lower leg anterior muscle compartment. Thus, LDH response may be due to the size of the muscle group affected by the fatiguing protocol. The differences in CK and LDH responses are most likely due to the structurally different areas where they are sequestered within the muscle sarcomere and are dependent on the site of primary mechanical muscle damage.

Classically, variations of CK are correlated with perceptions of soreness that could be attenuated with cold therapy. In the present study, subjects tended not to report greater benefits for DOMS with CWI when compared to other recovery interventions whereas performances and markers of muscle damages were positively affected. In a similar way, although cooling has inhibitory influences reporting beneficial effects on pain perception, some researchers reporting beneficial effect of cryotherapy on EIMD have not observed a concomittant effect on muscle soreness (Sellwood et al. 2007; Vaile et al. 2008c). Given the present athletes had prior familiarity with the DOMS pain scale, and were not influenced by doing multiple conditions, the influence of a comparative placebo condition may not factor in this study as it does in other studies (King and Duffield 2009). IN addition, in the present study, recovery was followed for $24 \mathrm{~h}$, whereas peak 
tenderness is reported to occur around $48 \mathrm{~h}$ post exercise and (Goodall and Howatson 2008) and as such, the time course for peak DOMS may have been missed.

\section{Conclusion}

Elite team sports are often required to perform high intensity intermittent exercise on consecutive days, and accordingly the use of recovery interventions between sessions may benefit the recovery process. As such, CWI seems to be more effective than TWI, CWT and PAS respectively on force loss restoration. It seems CWI offers the greatest restriction of the inflammatory process following high intensity contraction or damage. On the contrary, acute $30^{\prime \prime}$ all-out anaerobic performance seems to be accordingly improved faster following CWT as opposed to other recovery modes. That said, the improvements are only small and may not directly relate to all exercise bouts or physical demands. In summary, this study demonstrated that cold water immersion in $10^{\circ} \mathrm{C}$ for 15 min, compared to the temperate immersion or passive recovery, offers greater benefit on inflammation and subsequent performance 1 hours post exhaustive simulated team sports exercise in high trained team sports athletes. Moreover, the enhancement of one component of the anaerobic performances restoration may be attributed to a faster clearance of the metabolites with CWT therapy.

\section{Practical applications}

The results of the present study suggest that CWI and CWT may be a beneficial recovery intervention following and between training for team sports. In particular, where the task requires short maximal efforts during prolonged continuous high-intensity efforts on successive days, these two therapies may assist recovery to a greater degree than TWI interventions but must be used according to the goal (muscular damage or metabolites clearance) and the period (close or distant from the fatiguing exercise). However, particular attention must be paid on the exposure time and temperature of the water 


\section{References}

Bailey DM, Erith SJ, Griffin PJ, Dowson A, Brewer DS, Gant N, Williams C (2007) Influence of coldwater immersion on indices of muscle damage following prolonged intermittent shuttle running. J Sports Sci 25: 1163-1170

Boyas S, Nordez A, Cornu C, Guevel A (2006) Power responses of a rowing ergometer: mechanical sensors vs. Concept2 measurement system. Int J Sports Med 27: 830-833

Brancaccio P, Maffulli N, Buonauro R, Limongelli FM (2008) Serum enzyme monitoring in sports medicine. Clin Sports Med 27: 1-18, vii

Cochrane DJ (2004) Alternating hot and cold water immersion for athlete recovery: a review. Physical Therapy in Sport 5: 26-32

Coffey V, Leveritt M, Gill N (2004) Effect of recovery modality on 4-hour repeated treadmill running performance and changes in physiological variables. J Sci Med Sport 7: 1-10

Coté D, Prentice WE Jr, Hooker DN, EW. S (1988) Comparison of three treatment procedures for minimizing ankle sprain swelling. Phys Ther 68(7):1072-6

Eston R, Peters D (1999) Effects of cold water immersion on the symptoms of exercise-induced muscle damage. J Sports Sci 17: 231-238

French DN, Thompson KG, Garland SW, Barnes CA, Portas MD, Hood PE, Wilkes G (2008) The effects of contrast bathing and compression therapy on muscular performance. Med Sci Sports Exerc 40: 1297-1306

Friden J, Lieber RL (1992) Structural and mechanical basis of exercise-induced muscle injury. Med Sci Sports Exerc 24: 521-530

Friden J, Sjostrom M, Ekblom B (1983) Myofibrillar damage following intense eccentric exercise in man. Int J Sports Med 4: 170-176

Gill ND, Beaven CM, Cook C (2006) Effectiveness of post-match recovery strategies in rugby players. Br J Sports Med 40: 260-263

Goodall S, Howatson G (2008) The effects of multiple cold water immersions on indices of muscle damage. J Sports Sci Med 7: 235-241

Halson SL, Quod MJ, Martin DT, Gardner AS, Ebert TR, Laursen PB (2008) Physiological Responses to Cold Water Immersion Following Cycling in the Heat. Int J Sports Physiol Perform 3: 331-346

Hing WA, White SG, Bouaaphone A, Lee P (2008) Contrast therapy--a systematic review. Phys Ther Sport 9: 148-161

Howatson G, Goodall S, van Someren KA (2009) The influence of cold water immersions on adaptation following a single bout of damaging exercise. Eur J Appl Physiol 105: 615-621

Ingram J, Dawson B, Goodman C, Wallman K, Beilby J (2009) Effect of water immersion methods on post-exercise recovery from simulated team sport exercise. J Sci Med Sport 12: 417-421

Ispirlidis I, Fatouros IG, Jamurtas AZ, Nikolaidis MG, Michailidis I, Douroudos I, Margonis K, Chatzinikolaou A, Kalistratos E, Katrabasas I, Alexiou V, Taxildaris K (2008) Time-course of changes in inflammatory and performance responses following a soccer game. Clin J Sport Med 18: 423-431

Jidovtseff B, Croisier JL, Scimar N, Demoulin C, Maquet D, Crielaard JM (2008) The ability of isoinertial assessment to monitor specific training effects. J Sports Med Phys Fitness 48: 55-64

King M, Duffield R (2009) The effects of recovery interventions on consecutive days of intermittent sprint exercise. J Strength Cond Res 23: 1795-1802

Lollgen H, von Nieding G, Koppenhagen K, Kersting F, Just H (1981) Hemodynamic response to graded water immersion. Klin Wochenschr 59: 623-628

Magalhaes J, Rebelo A, Oliveira E, Silva JR, Marques F, Ascensao A (2010) Impact of Loughborough Intermittent Shuttle Test versus soccer match on physiological, biochemical and neuromuscular parameters. Eur J Appl Physiol 108: 39-48

Ravier G, Dugue B, Grappe F, Rouillon JD (2006) Maximal accumulated oxygen deficit and blood responses of ammonia, lactate and $\mathrm{pH}$ after anaerobic test: a comparison between international and national elite karate athletes. Int J Sports Med 27: 810-817

Reilly T, Ekblom B (2005) The use of recovery methods post-exercise. J Sports Sci 23: 619-627 
Rodenburg JB, Bar PR, De Boer RW (1993) Relations between muscle soreness and biochemical and functional outcomes of eccentric exercise. J Appl Physiol 74: 2976-2983

Rowsell GJ, Coutts AJ, Reaburn P, Hill-Haas S (2009) Effects of cold-water immersion on physical performance between successive matches in high-performance junior male soccer players. J Sports Sci 27: 565-573

Sellwood KL, Brukner P, Williams D, Nicol A, Hinman R (2007) Ice-water immersion and delayed-onset muscle soreness: a randomised controlled trial. Br J Sports Med 41: 392-397

Smith C, Kruger MJ, Smith RM, Myburgh KH (2008) The inflammatory response to skeletal muscle injury: illuminating complexities. Sports Med 38: 947-969

Smith LL (1991) Acute inflammation: the underlying mechanism in delayed onset muscle soreness? Med Sci Sports Exerc 23: 542-551

Stacey DL, Gibala MJ, Martin Ginis KA, Timmons BW (2010) Effects of Recovery Method on Performance, Immune Changes, and Psychological Outcomes. J Orthop Sports Phys Ther

Tomlin DL, Wenger HA (2001) The relationship between aerobic fitness and recovery from high intensity intermittent exercise. Sports Med 31: 1-11

Vaile J, Halson S, Gill N, Dawson B (2008a) Effect of cold water immersion on repeat cycling performance and thermoregulation in the heat. J Sports Sci 26: 431-440

Vaile J, Halson S, Gill N, Dawson B (2008b) Effect of hydrotherapy on recovery from fatigue. Int J Sports Med 29: 539-544

Vaile J, Halson S, Gill N, Dawson B (2008c) Effect of hydrotherapy on the signs and symptoms of delayed onset muscle soreness. Eur J Appl Physiol 102: 447-455

Vaile J, O'Hagan C, Stefanovic B, Walker M, Gill N, Askew CD (2010) Effect of cold water immersion on repeated cycling performance and limb blood flow. Br J Sports Med

Vaile JM, Gill ND, Blazevich AJ (2007) The effect of contrast water therapy on symptoms of delayed onset muscle soreness. J Strength Cond Res 21: 697-702

Versey N, Halson S, Dawson B (2010) Effect of contrast water therapy duration on recovery of cycling performance: a dose-response study. Eur J Appl Physiol

Wilcock IM, Cronin JB, Hing WA (2006) Physiological response to water immersion: a method for sport recovery? Sports Med 36: 747-765

\section{Figure and tables}


Figure 1:

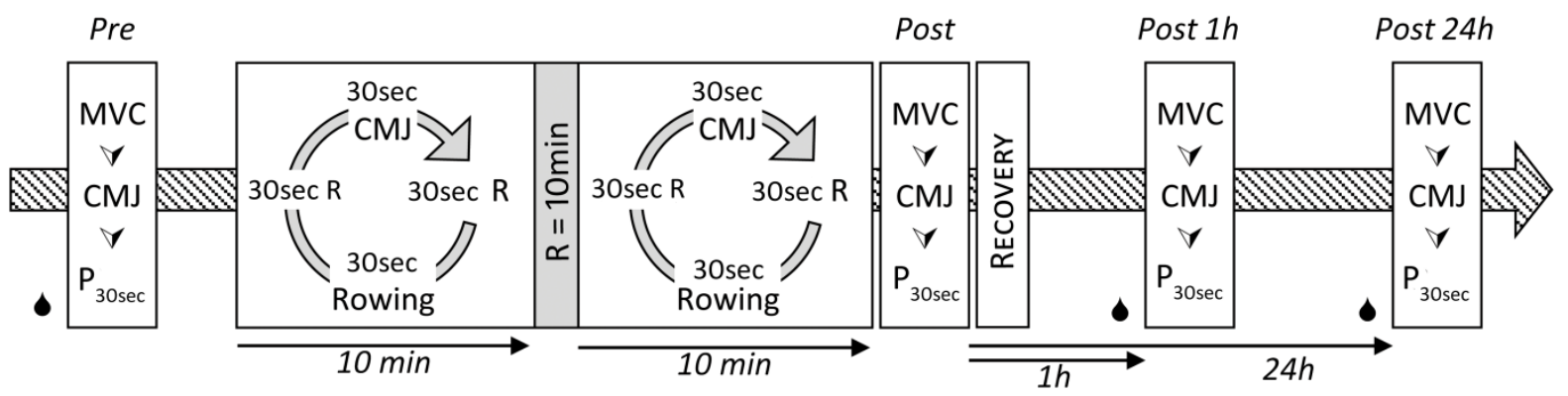

3

4

5

6

7

8

9

10

11

12 
Figure 2:
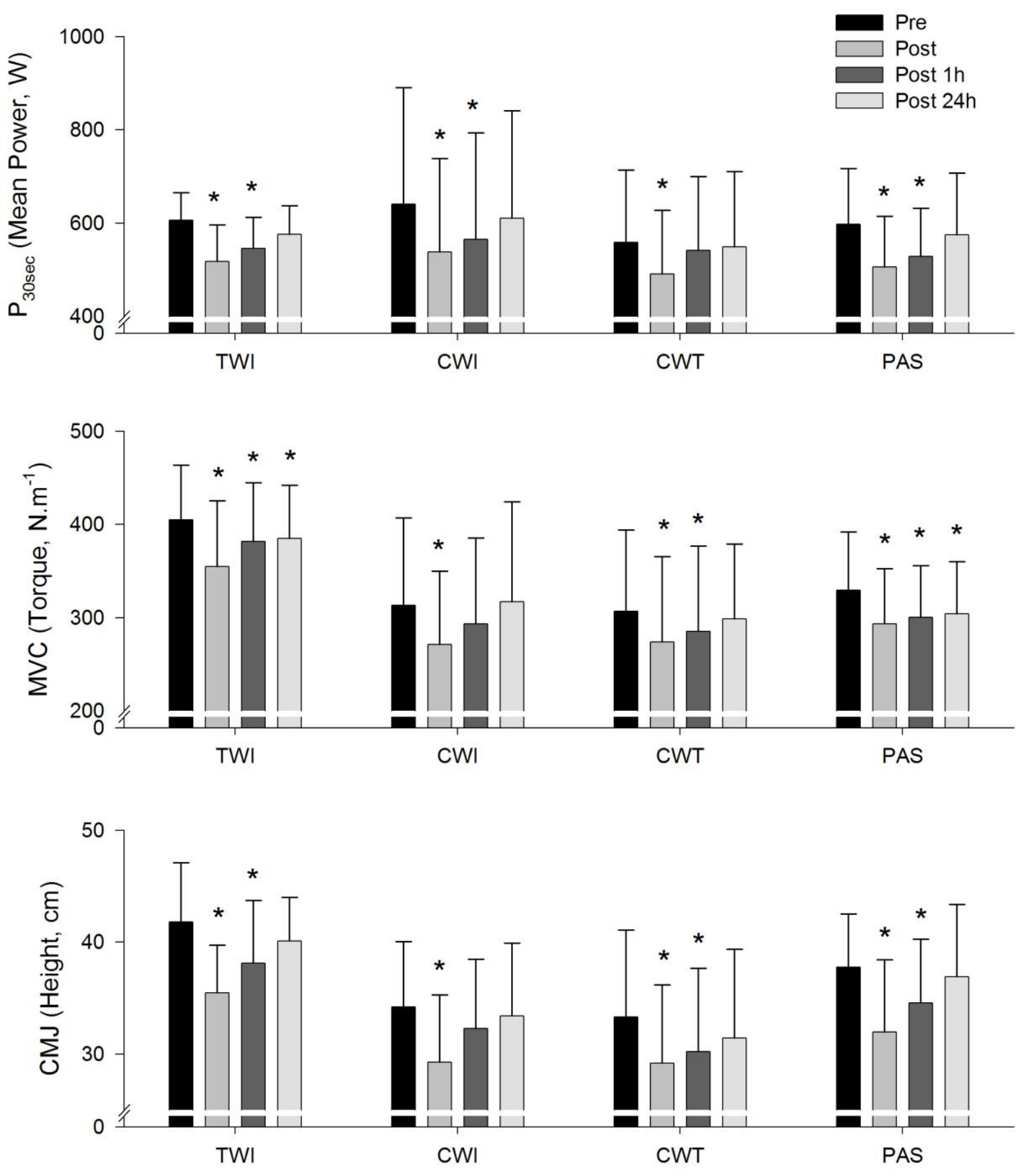
Figure 3:
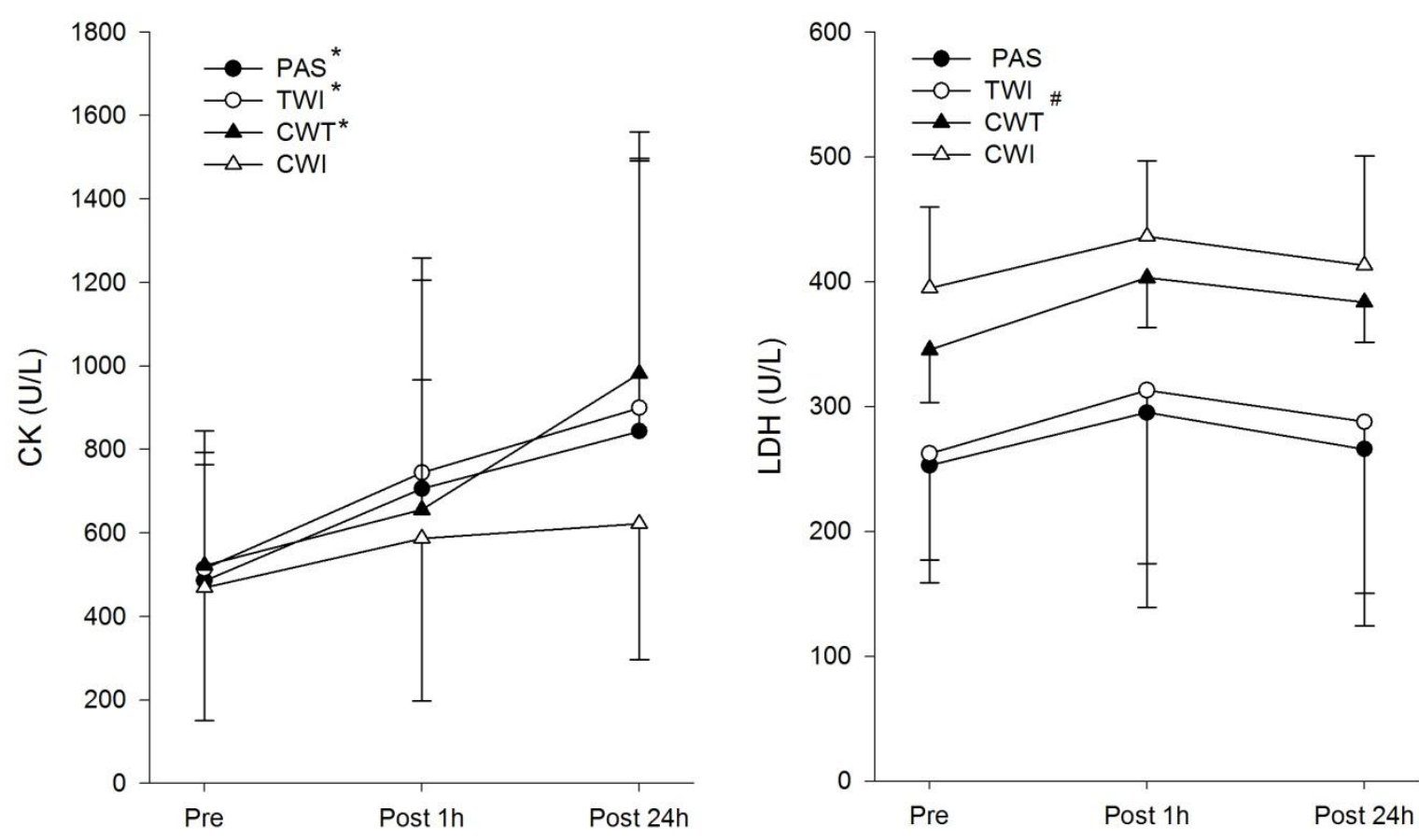

2 
2 Figure 4:

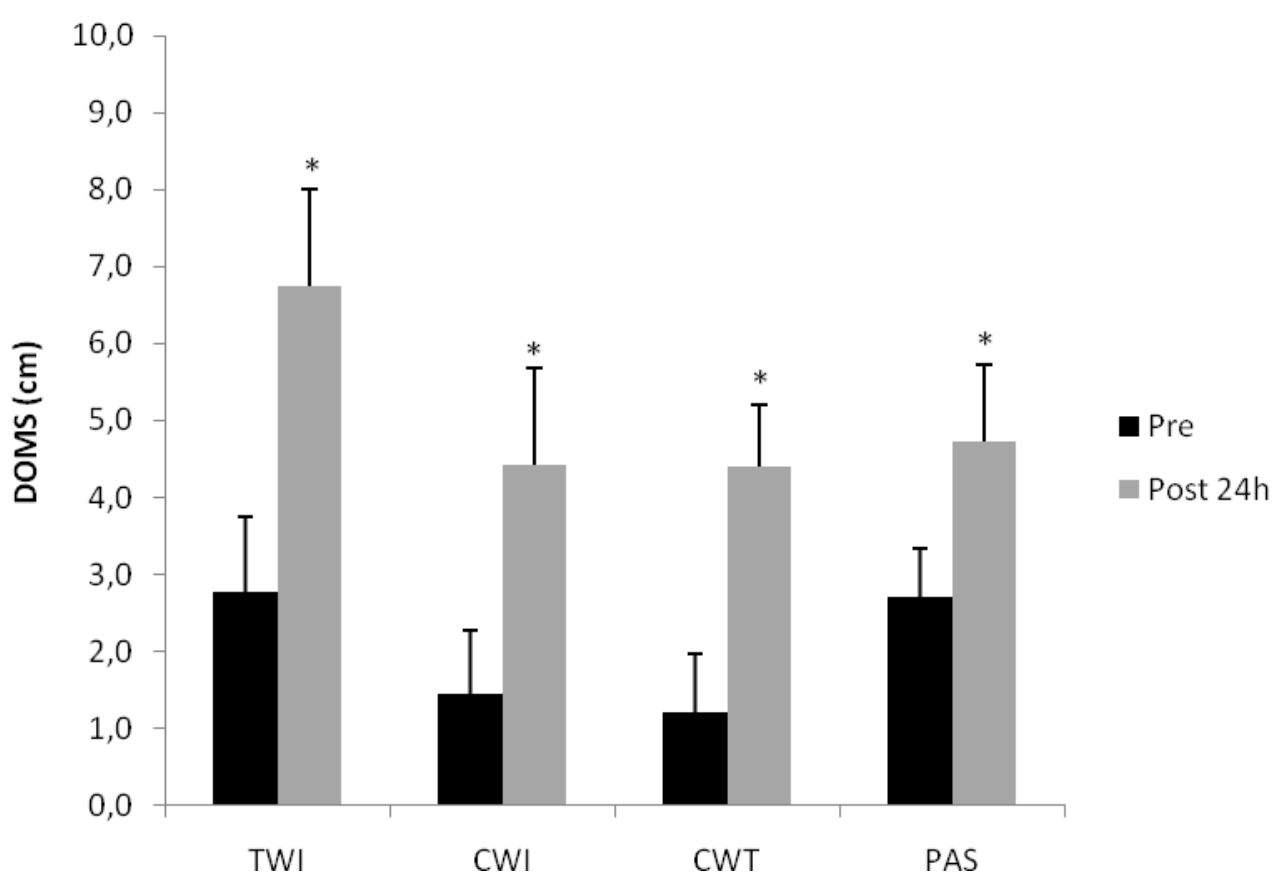

3 


\begin{tabular}{|c|c|c|c|c|}
\hline \multirow[b]{2}{*}{ Analyse } & & \multicolumn{3}{|c|}{ Mean Values (range) } \\
\hline & & Pre-exercise & Post $1 \mathrm{~h}$ & Post 24h \\
\hline \multirow{4}{*}{ Leukocytes $\left(10^{9} \cdot \mathrm{L}^{-1}\right)$} & PAS & $5.5(4.5-7.5)$ & $7.6(5.2-10.4)^{*}$ & $5.2(3.2-8.2)$ \\
\hline & CWI & $7.2(4.4-10.7)$ & $9.4(4.9-14.8)$ & $7.4(5.2-11.5)$ \\
\hline & TWI & $5.1(2.8-7.9)$ & $10.0(4.3-14.6)^{*}$ & $5.7(4-8.1)$ \\
\hline & CWT & $5.7(4.1-8.2)$ & $9.6(4.5-17)^{*}$ & $6.2(4.2-8)$ \\
\hline \multirow{4}{*}{ Neutrophils $\left(10^{9} \cdot \mathrm{L}^{-1}\right)$} & PAS & $2.67(1.61-4.17)$ & $4.91(2.10-7.98)^{*}$ & $2.67(1.48-4.98)$ \\
\hline & CWI & $2.23(0.99-3.80)$ & 3.77 (1.32-7.95) & $2.56(1.39-4.74)$ \\
\hline & TWI & $1.06(0.0-4.17)$ & $2.24(0.0-10.21)^{*}$ & $2.77(0.0-5.08)$ \\
\hline & CWT & $3.31(1.95-5.12)$ & $7.73(3.03-14.16)^{*}$ & $4.40(3.29-5.98)$ \\
\hline \multirow{4}{*}{ Lymphocytes $\left(10^{9} \cdot \mathrm{L}^{-1}\right)$} & PAS & $2.58(1.57-7.46)$ & $2.75(0.90-10.41)$ & $2.78(1.34-8.17)$ \\
\hline & CWI & $4.36(2.59-6.15)$ & $5.06(2.75-10.08)$ & $4.27(2.90-6.41)$ \\
\hline & TWI & $2.74(1.63-7.10)$ & $5.04(0.0-11.70)$ & $2.31(1.65-5.50)$ \\
\hline & CWT & $1.78(1.36-2.15)$ & $1.20(0.86-1.46)$ & $1.81(1.51-2.05)$ \\
\hline \multirow{4}{*}{ Monocytes $\left(10^{9} \cdot \mathrm{L}^{-1}\right)$} & PAS & $0.40(0.33-0.51)$ & $0.52(0.34-0.87)^{*}$ & $0.42(0.25-0.63)$ \\
\hline & CWI & $0.35(0.14-0.61)$ & $0.30(0.16-0.62)$ & $0.36(0.14-0.82)$ \\
\hline & TWI & $0.23(0.00-0.99)$ & $0.30(0.00-1.21)^{*}$ & $0.44(0.33-0.95)$ \\
\hline & CWT & $0.35(0.16-0.56)$ & $0.49(0.24-1.04) *$ & $0.39(0.35-0.50)$ \\
\hline \multirow{4}{*}{ Eosinophiles $\left(10^{9} \cdot \mathrm{L}^{-1}\right)$} & PAS & $0.23(0.06-0.60)$ & $0.16(0.03-0.29)$ & $0.16(0.04-0.34)$ \\
\hline & CWI & $0.20(0.07-0.45)$ & $0.23(0.10-0.43)$ & $0.22(0.10-0.38)$ \\
\hline & TWI & $0.07(0.08-0.32)$ & $0.05(0.0-0.32)$ & $0.16(0.0-0.30)$ \\
\hline & CWT & $0.19(0.06-0.30)$ & $0.13(0.03-0.2)$ & $0.16(0.05-0.30)$ \\
\hline \multirow{4}{*}{ Erythrocytes $\left(10^{12} \cdot \mathrm{L}^{-1}\right)$} & PAS & $4.9(4.3-5.6)$ & $4.8(4.4-5.1)$ & $4.8(4.5-5.3)$ \\
\hline & CWI & $4.8(4.5-5.4)$ & $4.9(4.7-5.5)$ & $4.7(4.3-5.2)$ \\
\hline & TWI & $5.0(4.35-5.81)$ & $5.0(3.24-5.47)$ & $5.0(3.85-5.35)$ \\
\hline & CWT & $4.7(3.9-5.1)$ & $4.6(3.8-4.9)$ & $4.7(4.0-4.9)$ \\
\hline \multirow{4}{*}{ Hémoglobine (g. $\mathrm{L}^{-1}$ ) } & PAS & 147 (129-165) & $144(135-153)$ & $145(135-161)$ \\
\hline & CWI & $139(117-157)$ & $142(127-158)$ & $136(119-153)$ \\
\hline & TWI & $138(49-157)$ & $138(107-152)$ & 141 (126-159) \\
\hline & CWT & $152(125-211)$ & $139(117-155)$ & 142 (121-149) \\
\hline \multirow{4}{*}{ Hématocrite (vol. fraction) } & PAS & $43(38-47)$ & $44(41-47)$ & $42(40-47)$ \\
\hline & CWI & $41(38.2-46.2)$ & $42(37.3-47.6)$ & $40(36.1-43.7)$ \\
\hline & TWI & $40(39.6-44.8)$ & $42(29.4-44.3)$ & $42(37.6-46.7)$ \\
\hline & CWT & $42(36.6-44.8)$ & $40(34.8-42.7)$ & $41(36.4-44.2)$ \\
\hline
\end{tabular}




\section{Figures legend}

3 Figure 1: Experimental design. MVC, maximal isometric voluntary contraction; CMJ, Vertical counter-movement

4 jump; $\mathrm{P}_{30 \text { sec }}, 30$ " all-out rowing exercise; $\bullet$, blood samples; $R$, Rest.

5 Figure 2: Mean \pm S.D Maximal isometric voluntary contraction (MVC), counter-movement jump (CMJ) and 6 mean power during $30 \mathrm{~s}$ all-out rowing exercise $\left(\mathrm{P}_{30 \mathrm{sec}}\right)$, for temperate water immersion (TWI), cold water 7 immersion (CWI), contrast water temperature (CWT) and passive (PAS) conditions. Group effect: no significant 8 difference between the groups for all values. Time effect: ${ }^{*}$, represents significant a difference to pre-exercise $9 \quad(P<0.05)$.

Figure 3: Mean \pm S.D creatine kinase (CK) and lactate dehydrogenase (LDH) before and following the exercise protocol for temperate water immersion (TWI), cold water immersion (CWI), contrast water temperature (CWT) and passive (PAS) conditions. Time effect: ${ }^{*}$, represents significant difference between Pre-exercise and Post $24 \mathrm{~h}$ measures $(P<0.05)$. \#, represents significant difference between Pre-exercise and Post $1 \mathrm{~h}$ measures $(P<0.05)$.

Figure 4: Mean \pm S.D Delayed onset muscle soreness (DOMS) for temperate water immersion (TWI), cold water immersion (CWI), contrast water temperature (CWT) and passive (PAS) groups before and $24 \mathrm{~h}$ after the damaging bout of exercise. Time effect: *, represents significant difference between Pre-exercise and Post $24 \mathrm{~h}$ measures $(P<0.05)$.

\section{Tables legend}

Table 1: Mean \pm SD haematological results before and following the exercise protocol for temperate water immersion (TWI), cold water immersion (CWI), contrast water temperature (CWT) and passive (PAS) conditions. Group effect: no significant difference between the groups for all values.

23 Time effect: *, represents significant difference with pre-exercise $(P<0.05)$. 